\title{
Perspectives on Snow Avalanche Dynamics Research
}

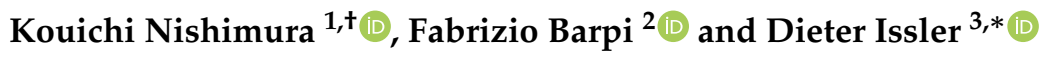 \\ 1 Graduate School of Environmental Studies, Nagoya University, Furo-cho, Chikusa-ku, \\ Nagoya 464-8601, Japan; knishi99@gmail.com \\ 2 Department of Structural, Geotechnical and Building Engineering, Politecnico di Torino, Corso Duca degli \\ Abruzzi 24, 10129 Torino, Italy; fabrizio.barpi@polito.it \\ 3 Division of Natural Hazards, Norwegian Geotechnical Institute, P.O. Box 3930 Ullevål Stadion, \\ 0806 Oslo, Norway \\ * Correspondence: di@ngi.no; Tel.: +47-469-87-346 \\ † Mailing address: 3301-32, Kita 8-jo Nishi 3-chome, Kita-ku, Sapporo 060-0808, Japan.
}

Citation: Nishimura, K.; Barpi, F.;

Issler, D. Perspectives on Snow

Avalanche Dynamics Research.

Geosciences 2021, 11, 57. https://

doi.org/10.3390/geosciences11020057

Academic Editors: Paolo Frattini and Jesús Martínez-Frías

Received: 4 January 2021

Accepted: 26 January 2021

Published: 29 January 2021

Publisher's Note: MDPI stays neutral with regard to jurisdictional clai$\mathrm{ms}$ in published maps and institutional affiliations.

Copyright: $(\odot 2021$ by the authors. Licensee MDPI, Basel, Switzerland. This article is an open access article distributed under the terms and conditions of the Creative Commons Attribution (CC BY) license (https:// creativecommons.org/licenses/by/ $4.0 /)$.

\begin{abstract}
As an introduction for non-specialists to the Special Issue on snow avalanche dynamics, this paper first outlines how understanding the dynamics of snow avalanches can contribute to reducing risk for settlements and infrastructure. The main knowledge gaps in this field of research concern (i) the properties of the flow regimes and the transitions between them, and (ii) the dynamics of mass change due to erosion and deposition. These two aspects are intertwined and determine not only the reach of an avalanche, but also its velocity, course and impact pressure. Experimental studies described in this Special Issue comprise a wide range of scales from small rotating drums to real snow avalanches. In addition, several papers describe post-event field surveys of specific avalanches and analyze them using different methods and techniques, demonstrating how valuable qualitative insight can be gained in this way. The theoretical developments range from exploratory studies of fluid-particle interactions to a comprehensive review of half a century of avalanche flow modeling in Russia.
\end{abstract}

Keywords: snow avalanches mitigation; experiments; numerical models; flow regimes; entrainment

\section{Why a Special Issue on Snow Avalanche Dynamics?}

Among the natural hazards driven by gravitational mass flows (GMFs), snow avalanches have particular characteristics: Together with rock falls and debris flows, they are among the most frequent hazard phenomena, with millions of events of all sizes occurring each year. Seen over the entire world, they are not among the most deadly natural hazards, but in several mountainous countries in moderate climate zones, they exact the highest death toll of all GMFs when averaged over decades. Additionally, they have important consequences for economic activity in highly developed countries because they can severely disrupt railway and road traffic. The destructive potential of snow avalanches ranges widely; it is certainly smaller than that of a large volcanic eruption or a gigantic rock avalanche, yet the number of sites where snow avalanches can occur and their frequency are incomparably larger. It is well known that even a small snow sluff can be deadly for an individual who gets caught in it.

Fortunately, snow avalanches are one of the natural hazards that can most effectively be mitigated. Over the course of more than a century, a wide range of protection measures have been developed. To classify them, express the societal risk due to avalanches as

$$
R=\sum_{s, i} P(s) E_{i}(s) V_{i}(s),
$$

where $s$ represents a specific scenario characterized by, e.g., the probability or size of the event, its run-out distance or its maximum pressure. $P(s)$ is the annual probability of 
scenario $s$ occurring, $E_{i}(s)$ is the exposure measured by the number of persons present or the monetary value of buildings reached under the given scenario, and $V_{i}(s)$ is the vulnerability of persons or objects in that situation. The summation over scenarios will be an integration if $s$ is a continuous variable. $E$ and $V$ are considered multi-dimensional objects, each component $i=1,2, \ldots, n$ representing, e.g., a building within the study area. Thus, one can distinguish three general strategies for minimizing the risk posed by avalanches: (i) Reduce $P$, i.e., prevent the occurrence of avalanches, e.g., by building snow-cover support structures in the release area. (ii) Minimize the exposure E. For people, this can be done by means of, e.g., avalanche warning, evacuations and road closures in times when $P$ is significant, or construction of avalanche sheds, tunnels or dams if one wishes to avoid traffic restrictions. With regard to buildings, hazard mapping helps to avoid construction in areas where $P$ is above an acceptable threshold. (iii) Reduce the vulnerability $V$ in the case of a hit with the help of avalanche rescue beacons and similar safety equipment or by dimensioning exposed structures to withstand the avalanche pressure. The artificial release of avalanches can be considered a hybrid of approach (i) and (ii) in that the probability of large-avalanche scenarios is reduced at the expense of increased probability of small avalanches, for which the exposure and/or vulnerability are negligible.

Considering the temporal and spatial scales, the relevant physical processes, and the need of knowledge for mitigation purposes, three main topics can be distinguished in avalanche science, namely

- "avalanche geography", comprising the connection between geographic and climatic variables and the probability and severity of avalanching, the geomorphologic effects of avalanches, and the socio-economic aspects of avalanche hazard,

- $\quad$ avalanche formation, including the sequence of processes leading to fracture, its probability under given conditions, and the extent and depth of the released snow slab, and

- avalanche dynamics, including the study of flow regimes, density, velocity, snow entrainment and deposition as well as the interaction of avalanches with obstacles.

With regard to the general mitigation strategies mentioned above, knowledge of avalanche dynamics can help to reduce both exposure and vulnerability: Given an avalanche scenario $s$ characterized by the extent of the release area, the fracture depth and the snow properties along the path, one can calculate the area affected by the flow and the distribution of velocity, flow depth and pressure along the path. If avalanche forecasting at the site-specific level estimates the probability of the scenario, the probability of an avalanche hitting a specific object can be obtained. If the scenario corresponds to a rare event with the threshold probability applied in land-use planning (ranging from $0.01 \mathrm{y}^{-1}$ in some countries to $0.0002 \mathrm{y}^{-1}$ for public buildings in Norway), hazardous terrain can be identified and construction banned or restricted. Knowing the velocity and density of such a "design avalanche", the optimum placement and dimensions of protective measures like deflecting or catching dams may be determined. In all three cases, knowledge of avalanche dynamics contributes to minimizing the exposure $\boldsymbol{E}(s)$. When it comes to minimize the vulnerability $V(s)$ of exposed objects, knowledge of the avalanche flow depth and pressure distribution at a given point is essential for correctly dimensioning the building.

Important contributions to the study of snow avalanches have been made in well over a dozen countries for nearly a century, with pioneering works dating back as far as 150 years [1]. It may thus be surprising for outsiders that-despite substantial progressmany fundamental questions of primary practical significance still lack a well-founded and comprehensive answer. In the authors' opinion, the most pressing ones are the following:

1. How can one estimate the release probability in a given slope with given statistical properties of the climate (distributions of temperature, precipitation and wind)? How do the release area and fracture depth vary with the return period and climatic conditions?

2. What are the physical mechanisms that allow some snow avalanches to attain very long run-out? How likely are the conditions under which such flows can occur? 
3. What are the mechanisms responsible for snow entrainment and deposition, and how can they be modeled adequately?

4. How can one compute the pressure distribution on a building hit by a snow avalanche?

5. How can avalanche activity be monitored, reliably and affordably, in near-real-time and over large areas?

Problems 2-4 primarily fall into the realm of avalanche dynamics. This provided a strong motivation for collecting current research on avalanche dynamics in the present Special Issue and to examine how progress can be achieved in answering these questions, which also was reflected in the call for papers.

In the following sections, we will briefly discuss how the papers in this Special Issue relate to the key questions listed above, what they have achieved and what pointers they give for future work.

\section{The Underrated Potential of Field Observations}

Several contributed papers describe historic avalanches, which span more than two centuries, from 1803 to 2017. Two sites are in the Pyrenees [2,3], three in Switzerland [4] and one in Italy [5]. These investigations differ widely with regard to the extent of the field work, the applied observational techniques, and the analyses performed. Typical difficulties are time and access constraints in the aftermath of a disaster, which often severely limit the type and amount of data that can be collected. When investigating historic avalanches, the challenge is that most traces have long since vanished. The collected papers demonstrate various possibilities to overcome such limitations, and we hope that they will inspire many valuable field investigations in the future.

In [2], three powerful approaches were combined to gain a better understanding of an extraordinary avalanche in the Pyrenees that eradicated an entire hamlet in the beginning of the 19th century: first, tenacious searching through old documents and interviews with elderly residents not only yielded more precise information on the event itself and its conditions, but also allowed reconstruction of the avalanche history of that path through one century. Second, combining this information with an extensive dendrochronological investigation of the concerned area puts fairly stringent constraints on the initial conditions and extent of the event. Third, numerical simulations with an advanced avalanche flow model, including the 3D simulation of the suspension layer ("powder-snow cloud") of the avalanche, tested different scenarios within the observational constraints and revealed shortcomings in our present capabilities for modeling mixed dry-snow avalanches.

The remarkable large powder-snow avalanche in Arinsal, Andorra, in 1996 is wellknown among avalanche specialists. However, the available information on the conditions leading to the event, on the flow evolution and extent, the damage it wreaked and how the hazard was managed is critically evaluated and comprehensively described for the first time in [3]. Readers of the paper will also appreciate how deadly the avalanche would have been if the danger had not been recognized in time and decisive action taken.

Similarly, there has not been a readily accessible report on, and analysis of, three widely different powder-snow avalanches that occurred in the course of three weeks in Switzerland in 1995. In all three cases, the extent of field work was severely limited, but in [4] it is shown how valuable information can nevertheless be inferred by combining observations, non-observations (i.e., observations that something did not occur) and simple mechanical estimates. Field work — described in [5]—on one of the deadliest avalanches in Europe in the past half century, which completely destroyed a hotel in the central Apennines, was mainly limited to a survey of the release area and the forest damage. These observations can, however, be combined with information in the media and mechanical analyses of avalanche movement at counterslopes or in gully bends and interactions between an avalanche and trees or buildings to derive constraints on the velocity, pressure and entrainment behavior of this event.

The four mentioned papers can serve several purposes: for one, they show clearly that rare avalanches may behave very differently from more frequent events in the same path 
if the right weather and snowpack conditions combine. This must be a valuable lesson to learn for all avalanche professionals who are involved in avalanche hazard mapping. Second, they demonstrate to avalanche researchers that we still neither have a complete understanding of the full breadth of avalanche behavior nor the capability of capturingand predicting - such behavior in our models. Third, there are many further remarkable or unusual avalanche events that deserve to be analyzed in more detail and documented in a freely accessible way (preferably collected in one website). Such a collection of event reports could both serve as case-based (self-)teaching material for avalanche professionals and for the validation of new avalanche flow models.

Incidentally, the latter task - model calibration and validation-is far from trivial for present-day two- or three-dimensional models: they should not just reproduce the run-out distance and-if measured-the velocity of a number of known events, but also the extent and depth of the deposits, which represent a continuum of variables. Moreover, the initial conditions of the avalanches in the calibration sample are often not precisely known, and there is often also a large uncertainty concerning the frequency of the observed events. The paper [6] continues earlier work to develop a well-founded yet practically applicable method for accomplishing this. To make the best use of available information with varying degrees of certainty, Bayesian methods are applied. The unknown error induced by the deterministic run-out model is simulated as noise, leading to probability distributions for the model parameters rather than a unique calibration function and to corresponding spatial distributions of run-out probability.

\section{Avalanche Experiments-In Large Sites, Small Sites or the Laboratory?}

When it comes to understanding the basic mechanisms that determine avalanche motion, field observations are a valuable complement to, but not a replacement for, targeted experiments under controlled or at least well-monitored conditions. Laboratory experiments (including outdoor chutes) allow the best control of initial and boundary conditions, as well as the most detailed instrumentation. However, the scaling behavior (one to three orders of magnitude in linear dimensions, time, velocity and stresses) needs to be thoroughly investigated, which is not an easy task. Moreover, when snow is used in laboratory experiments, the particle size cannot readily be scaled with the linear dimensions. If other granular materials are used instead, their properties may differ significantly (e.g., the restitution coefficient, cohesion, permeability, internal and bed friction angles), which poses problems when transferring the experimental results to snow avalanches. In particular, the intermediate or fluidized flow regime that determines the behavior of the front of dry-snow avalanches [4] is not readily reproduced in laboratory experiments without special devices [7].

Such considerations limit the direct applicability of the experiments presented in [8], which use snow particles with diameters of $\leq 1 \mathrm{~mm}, 1-2 \mathrm{~mm}$ and $2-4 \mathrm{~mm}$ in a rotating drum of only $118 \mathrm{~mm}$ in diameter-they are probably among the smallest granular-flow experiments reported in the literature (cf. the rotating-drum experiments presented in $[9,10]$ ). In exchange for these limitations, they allow steady-state measurements over extended time periods. Entrainment and deposition are an integral element of the flows, and particle motion can be studied by means of well-established particle image velocimetry (PIV) techniques.

Setting up full-scale avalanche experiments at large sites is difficult due to the large forces from large and fast avalanches and correspondingly expensive. It is desirable that experiments with a wide range of sensors be continued at the two existing large sitesVallée de la Sionne in Switzerland and Ryggfonn in Norway - and the medium-size site Col du Lautaret in France, because they produce a wealth of data of fundamental importance. At small sites, the velocities, pressures and moments on pylons are typically smaller by factors of 3,10 and 100, respectively. Equipping the site is accordingly less expensive and there is better control on avalanche size. The absence of a significant suspension layer facilitates direct visual observation [11], and the limited size of the path makes detailed 
field work based on numerous snow pits feasible [12]. In the past, small sites like Revolving Door [11] or Monte Pizzac [12] have yielded important results, but they all ceased operation after a few seasons, without exhausting their full potential. The newest site in this list is Seehore in Piemont, Italy, for which the present Special Issue has served as the decisive incentive to analyze and publish the collected data in a coherent fashion [13]. One may hope that a consortium of different institutions will form to establish a small test site, equip it with innovative sensors, and run it over an extended period. A wide spectrum of measurements on small avalanches will provide opportunity for investigating the scaling behavior of avalanche flows [14,15] without the uncertainties due to substitute materials or the scale mismatches between particle size and flow depth that may arise in small-scale laboratory experiments with snow [8].

In this Special Issue, the paper [16] proposes a classification of the seismic signals from avalanches according to the duration, amplitude and frequency content of different stages of the spectrograms and demonstrates that different classes correlate with different dominant flow regimes. These results were obtained as the fruit of a three decades-long effort in analyzing seismic signals from gravity mass flows. One may wonder whether a renewed effort at analyzing complex signals from other sensors available at the Vallée de la Sionne test site-most notably, frequency-modulated profiling radar and high-frequency pressure sensors-would not yield new, deeper insight into the processes inside avalanches.

\section{The Open Theoretical Questions}

Avalanche hazard mapping as one of the principal mitigation methods is contingent upon reliable prediction of avalanche run-out areas, even if there is no historical information on earlier events. The two opposite approaches to this task are the purely empirical one, exemplified by the topographical-statistical $\alpha-\beta$ model [17], and the physical one that uses deterministic release and flow models and relegates the role of chance to the probability distribution functions of the snow-cover properties. The former approach has been frequently used, even at large scales, e.g., in elaborating an avalanche susceptibility map for all of Norway [18], but in that case the result has been far from satisfactory because the statistical model does not capture climatic and forest-dependent variability.

The physical approach cannot be carried out completely yet because we still lack a first-principles avalanche model. Therefore, some of the intricate features of avalanche release and avalanche flow are summarily described by empirical relationships. A prime example of this are the so-called Voellmy-type run-out models, characterized by a bed friction law of the form [19]

$$
\tau_{b}=\mu_{0} \sigma_{n}+k \rho_{f} u^{2}
$$

where $\tau_{b}$ is the bed shear stress, $\rho_{f}$ the mean flow density, $\sigma_{n}$ the normal stress at the flow bottom, $u$ the (depth-averaged) flow velocity, and $\mu_{0}$ and $k$ two dimensionless empirical friction coefficients representing dry Coulombian friction and drag at the bottom of the flow akin to the Chézy term in hydraulic models.

The first consistent formulation and numerical implementation of the Voellmy model in terms of depth-averaged balance equations for mass and momentum was already achieved in the 1960s in the former Soviet Union, but was largely unknown or ignored in the West. For a summary of that early model and its unique features like frontal entrainment, see Section 2 of the invited review paper [20] in this Special Issue and the references to the original papers therein. Weaknesses of the Voellmy friction law were soon perceived and led to a simple modification that imposes an upper bound on the bed shear stress [21]. Together with a new formula for erosion of the snow cover along the bottom of the flow, this was described in a now inaccessible report in Russian from 1977. A paper in English that was to be published in 1996 is included in this Special Issue [22], together with a comment paper that puts that early work into a modern perspective [23].

The inadequacy of the Voellmy friction law for describing the complex processes in (dry-snow) avalanches with flow regime changes and continual interaction with the snow cover was understood early on (e.g., [24,25]). Yet, in most hazard-mapping applications 
this deficiency is still countered with complex calibration tables, in which $\mu_{0}$ and $k$ vary by a factor up to 3 with avalanche return period and release volume, terrain characteristics and altitude (as a proxy for temperature) [26]. Thus, the principal goal of contemporary avalanche dynamics research is to formulate a comprehensive rheology of flowing snow that depends on measurable snow properties instead of the empirical coefficients $\mu_{0}$ and $k$. There is wide consensus that the two main aspects of this task are the correct description of flow regimes, including thermal effects like granulation of the flowing snow $[27,28]$, and an adequate formulation of erosion and entrainment under different conditions.

A candidate for replacing the Voellmy friction law is the $\mu(I)$ rheology [29], because it captures many aspects of dense dry granular flows in terms of the non-dimensional shear rate $I$,

$$
I \equiv \frac{2 d\|\mathbf{D}\|}{\sqrt{p / \rho}}
$$

where $d$ is the mean particle diameter, $p$ the pressure, $\rho$ the local flow density, $D_{i j} \equiv \frac{1}{2}\left(\partial_{j} u_{i}+\partial_{i} u_{j}\right)$ the shear rate tensor, and $\|\mathbf{D}\| \equiv \sqrt{2 \sum_{i, j} D_{i j} D_{j i}}$ its second invariant. The tensorial form of the Cauchy stress is modeled as

$$
\sigma_{i j}=-p \delta_{i j}+\tau_{i j}=-p \delta_{i j}+2 \mu(I) p \frac{D_{i j}}{\|\mathbf{D}\|},
$$

The constant volumetric particle concentration $c_{0}$ and friction coefficient $\mu_{0}$ of the Coulomb failure criterion are replaced by the relations

$$
c(I)=c_{s}-\alpha I, \quad \text { and } \quad \mu(I)=\mu_{s}+\frac{\mu_{d}-\mu_{s}}{I_{0} / I+1}
$$

where $c_{S}$ is the volumetric particle concentration at rest, $\alpha$ a shear dilation coefficient, $\mu_{s}<\mu_{d}$ the static $(I \rightarrow 0)$ and dynamic $(I \rightarrow \infty)$ friction coefficients , and $I_{0}$ indicatesloosely speaking - the middle of the $I$-range of applicability of the model. Values for typical granular materials are $c_{s} \sim 0.6, \alpha \sim 0.2,0.3<\mu_{s}<0.4,0.2<\mu_{d}-\mu_{s}<0.3$ and $I_{0} \sim 0.3$. Experiments mainly cover the range $0<I<0.5$. Equation (5) predicts that there cannot be stationary flows on slopes steeper than $\theta_{c}=\arctan \mu_{d}$.

Two-dimensional depth-averaged flow models with this rheology $[30,31]$ have been applied to laboratory experiments and pyroclastic flows, but not to real snow avalanches yet. In this Special Issue, the paper [32] takes a first step towards closing this gap by simulating experiments on a ski jump with flows of ping-pong balls, using the code from [30]. The novel experimental aspect is the semi-dilute head of the ping-pong ball avalanches, similar to what is observed in real dry-snow avalanches-a regime that smallscale laboratory experiments have not hitherto studied in detail. Further analysis will be needed to understand the reasons for the discrepancies between experiments and simulations with regard to velocity evolution and deposit shape: parts of the slope were probably steeper than the limit $\theta_{c}$ and aerodynamic forces on the light ping-pong balls are substantial.

This result emphasizes the importance of achieving a physically and mathematically sound description of different flow regimes and the transition between them. Pioneering laboratory experiments on steep slopes [33] show that granular flows can remain dense for $I \gg 0.5$ and that there are flow regimes not captured by the $\mu(I)$ rheology. This suggests that the $\mu(I)$ rheology needs to be extended so that it can describe dense flows on steep slopes. In [33], semi-dilute (fluidized) flows were observed only on very steep, bumpy slopes and with low or moderate discharges, i.e., under more restricted conditions than in real snow avalanches. This points at a hitherto underrated role of the interstitial air, the snow cover or both. Limited theoretical work on the role of pore air with regard to snow entrainment in powder-snow avalanches [34,35] and fluidization of dense avalanches [36] was started only some 70 to 80 years after avalanche observations were interpreted in this 
way in an almost forgotten brief newspaper note [37]. These studies are not conclusive yet, but they strongly suggest that the problems of entrainment and flow-regime changes are intimately connected.

Development of flow-regime-changing depth-averaged flow models has been started but has either not been pursued beyond a block model [38] or awaits the resolution of physical and mathematical inconsistencies [39,40]. A different approach is explored in the paper [41] of this Special Issue, namely the discrete element method (DEM) extended to include the interaction between the particles and the interstitial fluid. The model is applied, not to powder-snow avalanches, but to the mentioned experiments with ping-pong balls on a ski jump, i.e., to particles that are two orders of magnitude larger and less dense than snow grains. To obtain equations that can be solved on a workstation, a number of farreaching simplifications are made and the number of particles limited to 2000. At this stage of development, the way towards a model capable of simulating the suspension layer of mixed snow avalanches is still long. However, an approach of this kind can become a tool for studying the macroscopic effects of processes at the particle scale, like the development of instabilities and the effective rheology of a particle-air mixture that can be implemented in a traditional continuum model.

In [8], macroscopic rheological relations are inferred, not from DEM simulations, but from experimental data processed with PIV techniques. These authors use a traditional computational fluid dynamics (CFD) code with a spatially and temporally variable effective viscosity, which is matched to the experimental results. While this approach may be considered less than satisfactory from a purely theoretical point-of-view, it has the significant advantage of providing immediate visual insight into how the effective viscosity varies from one flow region to another and how these differences are determined by the macroscopic flow variables.

The long-standing problem of erosion, entrainment and deposition is directly addressed in four papers within this Special Issue and plays a significant role in a fifth: different erosion models are discussed in a review of Soviet/Russian avalanche dynamics research from the 1960s to present [20]. The finally published "historic" paper [22] presents the Grigorian-Ostroumov erosion formula for basal entrainment, which is one of the few such models that are essentially free of empirical parameters. In [23], the GrigorianOstroumov model is analyzed and compared to two other entrainment models that also treat the interface between the flow and the snow cover as a shock and determine the entrainment rate from the jump conditions for mass and momentum across the shock. This comparison is instructive as it reveals shortcomings in all three models and points towards improved versions. However, as mentioned above, the erosion problem likely must be solved in conjunction with the flow rheology.

In contrast, the paper [42] focuses on the back-calculation of two measured avalanches at Vallée de la Sionne that were released on the same day under very similar snow conditions, but behaved rather differently. The key result is that both avalanches can be captured quite well with a single set of friction parameters if both entrainment and deposition are included in the model. These results corroborate and extend the earlier finding [43] that different avalanches can be back-calculated with a smaller spread in the empirical friction coefficients if entrainment is included. It is noteworthy that the deposition formula for the depth-averaged flow model used in [42] was devised on the basis of depth-resolved numerical simulations with a granular rheology.

The fifth paper addressing the mechanics of erosion is unique within this Special Issue in that it discusses the modeling of debris flows [44]. For a long time, researchers studying more than a single type of gravity mass flow have emphasized both the underlying commonalities between these phenomena and the extra insight that can be gained from analyzing their differences [45-47]. While the most frequently used numerical methods for simulating debris flows and snow avalanches are very similar-depth-averaged mass and momentum balance equations are solved by shock-capturing finite-difference, finitevolume or finite-element techniques-widely different concepts are applied in formulating 
erosion rates. As there seems to be a continuous transition from normal river flow over hyper-concentrated flow to debris flow, debris flow models often employ concepts from river hydraulics based on the equilibrium between erosion and deposition due to the (limited) transport capacity of the river. It seems that very few if any of the proposed erosion models for debris flows can be applied to snow avalanches, but if the concepts developed for snow avalanches $[20,22,23]$ can be adapted to cohesive bed materials, they might be useful for modeling rapidly eroding debris flows.

\section{How to Bring All Advances Together for Avalanche Hazard Mitigation?}

From a world-wide societal perspective, there is a need for avalanche hazard mitigation in two very different settings: (i) Poorly or moderately developed mountainous countries (and some developed but thinly populated ones) need methods and tools for reliable yet affordable mapping of avalanche hazard over large areas. Similarly, low-cost avalanche forecasting procedures for large areas are desirable. (ii) In highly developed mountainous regions, basic avalanche hazard mapping has been carried out already and regional avalanche warning services are operative. For economic reasons, highly precise avalanche hazard mapping, reliable site-specific avalanche forecasting and a wide spectrum of effective constructive protection measures are sought.

To meet these needs, avalanche research addressing the questions listed at the end of Section 1 is expected to have the largest impact. Items 2, 3 and 4 are intimately related to avalanche dynamics. Several of the papers collected in this Special Issue respond to one or several of these research needs:

- $\quad$ Seismic methods are promising for surveying avalanche activity (item 5) and are in many respects complementary to satellite- or aircraft-based imaging. The road towards an operative seismic real-time monitoring network is full of challenges, but the paper [16] represents one piece in the puzzle. For recent related but complementary work, also see [48].

- In this Special Issue, only [41] explores the problem of flow regimes (item 2), but much more work is needed to arrive at a practical tool. The observational papers [2-4] highlight the challenges and provide opportunities for model validation. The latter task is non-trivial, however; it is addressed in [6].

- With regard to erosion and entrainment (item 3), several of the entrainment models summarized in the review [20] are worth a fresh look in view of recent experimental data on avalanche mass balance. In [23], avenues for improving the erosion model of [22] and two conceptually related, parameter-free entrainment models are outlined. The paper [42] convincingly shows that realistic back-calculations of several avalanche events with the same parameter set require modeling of both entrainment and deposition.

- There is an evident capability gap when it comes to modeling the impact pressure distribution on obstacles with complex shapes. The pioneering work of [49] and the more recent attempt of [50] need to be developed further into a tool for practical work. None of the papers in this Special Issue address this need, but the experimental results reported in [13] and the observations in [2-5] may provide opportunities for validating a future model.

The guest editors of this Special Issue hope that it will inspire its readers to tackle one or another of the identified knowledge gaps and contribute both to the advancement of a fascinating field of science and to improved protection against avalanche disasters.

Author Contributions: Conceptualization and preparation of original draft, D.I.; writing-review and editing, all authors. All authors have read and agreed to the published version of the manuscript.

Funding: Part of this work was funded by the special grant for snow avalanche research from the Norwegian Ministry of Oil and Energy, administrated by the Norwegian Water Resources and Energy Directorate (NVE). 
Acknowledgments: The guest editors are grateful to all contributors to this Special Issue for responding to the call and contributing their relevant work, in some cases under a tight time schedule or in their spare time without funding. We also wish to thank all reviewers who have contributed with insightful remarks on the submitted manuscripts (including this one), often responding within a very short time. It was a pleasure to collaborate with Richard Li of MDPI and his team of competent and efficient editorial assistants.

Conflicts of Interest: The authors declare no conflict of interest. The funders had no role in the design of the study or interpretation of data, in the writing of the manuscript, or in the decision to publish the results.

\section{References}

1. Ancey, C.; Jóhannesson, T.; Bakkehøi, S.; Lied, K.; Birkeland, K.; Nishimura, K.; Decker, R.; Pudasaini, S.P.; Hutter, K.; Schaerer, P.; et al. Some notes on the history of snow and avalanche research in Europe, Asia and America. ICE 2005, 3-11.

2. Oller, P.; Fischer, J.T.; Muntán, E. Multidisciplinary approach to reconstruct the historic avalanche that destroyed the village of Àrreu in 1803, Catalan Pyrenees. Geosciences 2020, 10, 169. [CrossRef]

3. Furdada, G.; Margalef, A.; Trapero, L.; Pons, M.; Areny, F.; Baró, M.; Reyes, A.; Guinau, M. The avalanche of Les Fonts d'Arinsal (Andorra): An example of a pure powder, dry snow avalanche. Geosciences 2020, 10, 126. [CrossRef]

4. Issler, D.; Gauer, P.; Schaer, M.; Keller, S. Inferences on Mixed Snow Avalanches from Field Observations. Geosciences 2020, 10, 2. [CrossRef]

5. Issler, D. The 2017 Rigopiano avalanche-Dynamics inferred from field observations. Geosciences 2020, 10, 466. [CrossRef]

6. Fischer, J.T.; Kofler, A.; Huber, A.; Fellin, W.; Mergili, M.; Oberguggenberger, M. Bayesian inference in snow avalanche simulation with r.avaflow. Geosciences 2020, 10, 191. [CrossRef]

7. Nishimura, K. Studies on the Fluidized Snow Dynamics; The Institute of Low Temperature Science, Hokkaido University: Sapporo, Japan, 1991.

8. Oda, K.; Nakamura, K.; Kobayashi, Y.; Suzumura, J. Inverse simulation for extracting the flow characteristics of snow avalanches based on Computational Fluid Dynamics. Geosciences 2020, 10, 221. [CrossRef]

9. Gray, J.M.N.T. Granular flow in partially filled slowly rotating drums. J. Fluid Mech. 2001, 441, 1-29. [CrossRef]

10. Heil, K.; Kaitna, R.; Fischer, J.T.; Reiweger, I. Granulation experiments with snow in a rotating drum. In Proceedings of the International Snow Science Workshop, Innsbruck, Austria, 7-12 October 2018; pp. 94-97.

11. Dent, J.D.; Burrell, K.J.; Schmidt, D.S.; Louge, M.Y.; Adams, E.E.; Jazbutis, T.G. Density, velocity and friction measurements in a dry-snow avalanche. Ann. Glaciol. 1998, 26, 247-252. [CrossRef]

12. Sovilla, B.; Sommavilla, F.; Tomaselli, A. Measurements of mass balance in dense snow avalanche events. Ann. Glaciol. 2001, 32, 230-236. [CrossRef]

13. Maggioni, M.; Barbero, M.; Barpi, F.; Borri-Brunetto, M.; De Biagi, V.; Freppaz, M.; Frigo, B.; Pallara, O.; Chiaia, B. Snow avalanche impact measurements at the Seehore test aite in Aosta Valley (NW Italian Alps). Geosciences 2019, 9, 471. [CrossRef]

14. Gauer, P. Comparison of avalanche front velocity measurements and implications for avalanche models. Cold Regions Sci. Technol. 2014, 97, 132-150. [CrossRef]

15. McClung, D.M.; Gauer, P. Maximum frontal speeds, alpha angles and deposit volumes of flowing snow avalanches. Cold Regions Sci. Technol. 2018, 153, 78-85. [CrossRef]

16. Suriñach, E.; Flores-Márquez, E.L.; Roig-Lafon, P.; Furdada, G.; Tapia, M. Estimation of avalanche development and frontal velocities based on the spectrogram of the seismic signals generated at the Vallée de la Sionne test site. Geosciences 2020, 10, 113. [CrossRef]

17. Bakkehøi, S.; Domaas, U.; Lied, K. Calculation of snow avalanche runout distance. Ann. Glaciol. 1983, 4, 24-29. [CrossRef]

18. Derron, M.H.; Sletten, K. Method for the Susceptibility Mapping of Snow Avalanches in Norway; Technical Report; NGU Report 2016.032; Geological Survey of Norway (NGU) and Institute of Geomatics and Risk Analysis (IGAR), University of Lausanne: Lausanne, Switzerland, 2016.

19. Voellmy, A. Über die Zerstörungskraft von Lawinen. Schweiz. Bauztg. 1955, 73, 159-165. 212-217. 246-249. $280-285$.

20. Eglit, M.E.; Yakubenko, A.; Zayko, J. A review of Russian snow avalanche models - from analytical solutions to novel 3D models. Geosciences 2020, 10, 77. [CrossRef]

21. Grigoryan, S.S. A new law of friction and mechanism for large-scale avalanches and landslides. Sov. Phys. Dokl. 1979, $24,110-111$.

22. Grigorian, S.S.; Ostroumov, A.V. On a continuum model for avalanche flow and its simplified variants. Geosciences 2020, 10, 35. [CrossRef]

23. Issler, D. Comments on "On a Continuum Model for Avalanche Flow and Its Simplified Variants" by S. S. Grigorian and A. V. Ostroumov. Geosciences 2020, 10, 96. [CrossRef]

24. Salm, B.; Gubler, H. Measurement and analysis of the motion of dense flow avalanches. Ann. Glaciol. 1985, 6, 26-34. [CrossRef]

25. Norem, H.; Irgens, F.; Schieldrop, B. Simulation of snow-avalanche flow in run-out zones. Ann. Glaciol. 1989, 13, 218-225. [CrossRef] 
26. Bartelt, P.; Bühler, Y.; Christen, M.; Deubelbeiss, Y.; Salz, M.; Schneider, M.; Schumacher, L. RAMMS::AVALANCHE User Manual; Version 1.7.0; WSL Institute for Snow and Avalanche Research: Davos, Switzerland, 2017.

27. Steinkogler, W.; Sovilla, B.; Lehning, M. Influence of snow cover properties on avalanche dynamics. Cold Regions Sci. Technol. 2014, 97, 121-131. [CrossRef]

28. Steinkogler, W.; Gaume, J.; Löwe, H.; Sovilla, B.; Lehning, M. Granulation of snow: From tumbler experiments to discrete element simulations. J. Geophys. Res. 2015, F120, 1107-1126. [CrossRef]

29. Jop, P.; Forterre, Y.; Pouliquen, O. A constitutive law for dense granular flows. Nature 2006, 441, 727-730. [CrossRef]

30. Maeno, F.; Hogg, A.J.; Sparks, R.S.J.; Matson, G.P. Unconfined slumping of a granular mass on a slope. Phys. Fluids 2013, 25, 023302. [CrossRef]

31. Baker, J.L.; Barker, T.; Gray, J.M.N.T. A two-dimensional depth-averaged $\mu(I)$-rheology for dense granular avalanches. J. Fluid Mech. 2016, 787, 367-395. [CrossRef]

32. Tsunematsu, K.; Maeno, F.; Nishimura, K. Application of inertia dependent flow friction model to snow avalanches. Geosciences 2020, 10, 436. [CrossRef]

33. Holyoake, A.J.; McElwaine, J.N. High-speed granular chute flows. J. Fluid Mech. 2012, 710, 35-71. [CrossRef]

34. Gauer, P.; Issler, D. Possible erosion mechanisms in snow avalanches. Ann. Glaciol. 2004, 38, 384-392. [CrossRef]

35. Carroll, C.S.; Louge, M.Y.; Turnbull, B. Frontal dynamics of powder snow avalanches. J. Geophys. Res. 2013, 118, 913-924. [CrossRef]

36. Issler, D. Notes on Fluidization of Snow Avalanches by Air Expulsion from the Snow Cover; NGI Technical Note 20140053-03-TN_rev0; Norwegian Geotechnical Institute: Oslo, Norway, 2017.

37. Zimmermann, E. Von Lawinen. Schweiz. Bauztg. 1936, 107, 284-286. (In German)

38. Issler, D.; Gauer, P. Exploring the significance of the fluidized flow regime for avalanche hazard mapping. Ann. Glaciol. 2008, 49, 193-198. [CrossRef]

39. Bartelt, P.; Buser, O.; Vera Valero, C.; Bühler, Y. Configurational energy and the formation of mixed flowing/powder snow and ice avalanches. Ann. Glaciol. 2016, 57, 179-188. [CrossRef]

40. Issler, D.; Jenkins, J.T.; McElwaine, J.N. Comments on avalanche flow models based on extensions of the concept of random kinetic energy. J. Glaciol. 2018, 64, 148-164. [CrossRef]

41. Niiya, H.; Awazu, A.; Nishimori, H. Simple particle model for low-density granular flow interacting with ambient fluid. Geosciences 2020, 10, 69. [CrossRef]

42. Rauter, M.; Köhler, A. Constraints on entrainment and deposition models in avalanche simulations from high-resolution radar data. Geosciences 2020, 10, 9. [CrossRef]

43. Sovilla, B.; Bartelt, P. Observations and modelling of snow avalanche entrainment. Nat. Haz. Earth Syst. Sci. 2002, 2, 169-179. [CrossRef]

44. Takebayashi, H.; Fujita, M. Numerical simulation of a debris flow on the basis of a two-dimensional continuum body model. Geosciences 2020, 10, 45. [CrossRef]

45. Simpson, J.E. Gravity Currents: In the Environment and the Laboratory; Ellis Horwood Series in Environmental Science; Ellis Horwood Ltd.: Chichester, UK, 1987.

46. McCaffrey, W.D.; Kneller, B.C.; Peakall, J. (Eds.) Particulate Gravity Currents; International Association of Sedimentologists, Blackwell Science Ltd.: Oxford, UK, 2001.

47. Jenkins, J.; Meiburg, E.; Valance, A. Fluid-Mediated Particle Transport in Geophysical Flows. In Proceedings of the Workshop and Conference hosted by the Kavli Institute of Theoretical Physics, University of California Santa Barbara, Santa Barbara, CA, USA, 23 September-20 December 2013. Available online: https://www.kitp.ucsb.edu/activities/geoflows13 (accessed on 4 January 2021).

48. Pérez-Guillén, C.; Tsunematsu, K.; Nishimura, K.; Issler, D. Seismic location and tracking of snow avalanches and slush flows on Mt. Fuji, Japan. Earth Surf. Dyn. 2019, 7, 989-1007. [CrossRef]

49. Kulibaba, V.S.; Eglit, M.E. Numerical modeling of an avalanche impact against an obstacle with account of snow compressibility. Ann. Glaciol. 2008, 49, 27-32. [CrossRef]

50. Rauter, M.; Fellin, W. Estimation of powder snow avalanche impact pressures with OpenFOAM. In Proceedings of the 12th OpenFOAM Workshop, University of Exeter, Exeter, UK, 24-27 July 2017. 